\title{
Relationship Between Renal Dysfunction and Oral Mucositis in Patients Undergoing Concurrent Chemoradiotherapy for Pharyngeal Cancer: A Retrospective Cohort Study
}

\author{
HIROFUMI MIZUNO ${ }^{1,2}$, HISATAKA MIYAI ${ }^{2}$, AYA YOKOI $^{2}$, TERUMASA KOBAYASHI ${ }^{2}$, \\ CHIAKI INABU ${ }^{3}$, TAKAYUKI MARUYAMA ${ }^{4}$, DAISUKE EKUNI ${ }^{2}$, NOBUYOSHI MIZUKAWA ${ }^{5}$, \\ SHIN KARIYA ${ }^{6}$, KAZUNORI NISHIZAKI ${ }^{6}$, YOSHIHIRO KIMATA ${ }^{7}$ and MANABU MORITA ${ }^{2}$ \\ ${ }^{1}$ Sasaki Dental Clinic, Komaki, Japan; \\ Departments of ${ }^{2}$ Preventive Dentistry, ${ }^{6}$ Otolaryngology-Head and Neck Surgery, and \\ ${ }^{7}$ Plastic and Reconstructive Surgery, Okayama University Graduate Schoolof Medicine, \\ Dentistry and Pharmaceutical Sciences, Okayama, Japan; \\ ${ }^{3}$ Junpukai Daiku Dental Clinic, Okayama, Japan; \\ ${ }^{4}$ Center for Innovative Clinical Medicine, and ${ }^{5}$ Department of Oral and Maxillofacial Reconstructive Surgery, \\ Okayama University Hospital, Okayama, Japan
}

\begin{abstract}
Background/Aim: The aim of this retrospective cohort study was to investigate the association between renal dysfunction (RD) and the development of oral mucositis (OM) in patients undergoing concurrent chemoradiotherapy (CCRT) for pharyngeal cancer including radiation to the oral cavity. Patients and Methods: Of 130 patients diagnosed as having pharyngeal cancer who received CCRT at the Okayama University Hospital Head and Neck Cancer Center, 44 were finally selected. Results: During the observation period, $24(54.5 \%)$ patients experienced severe OM (grade 3). The Cox proportional hazards regression model demonstrated that $R D$ (hazard ratio $(H R)=2.45,95 \%$ confidence interval $(C I)=1.067-6.116, \quad p=0.035) \quad$ and nasopharynx/oropharynx as center of the irradiated area (HR=2.56, 95\% CI=1.072-5.604, $p=0.034)$ were significantly associated with the incidence of severe OM (grade 3). Conclusion: In patients with pharyngeal cancer treated with $C C R T$ including radiation to the oral cavity, $R D$ at baseline can be a risk factor for developing severe OM.
\end{abstract}

This article is freely accessible online.

Correspondence to: Daisuke Ekuni, Department of Preventive Dentistry, Okayama University Graduate School of Medicine, Dentistry and Pharmaceutical Sciences, 2-5-1 Shikata-cho, Kita-ku, Okayama 700-8558, Japan. Tel: +81 862356712, Fax: +81 862356714, e-mail: dekuni7@md.okayama-u.ac.jp

Key Words: Head and neck cancer, oral mucositis, concurrent chemoradiotherapy, renal dysfunction, creatinine clearance.
In Japan in 2009, the number of patients with head and neck cancer (HNC) was estimated to be about 19,000, and approximately 3,300 patients died due to HNC (1). In order to reduce mortality, concurrent chemoradiotherapy (CCRT), which was found to be superior to radiotherapy with respect to progression-free survival, has been widely adopted as the standard non-surgical approach in HNC (2-4). However, since CCRT for HNC often uses a platinum-based regimen (5), CCRT induces side-effects including mucositis, xerostomia, oropharyngeal candidiasis, and neurosensory disorders (mucosal pain and taste dysfunction) (6). In particular, oral mucositis (OM) clearly has an adverse impact on patients' quality of life because of pain, i.e. difficulty in eating, swallowing and talking $(7,8)$. Furthermore, severe OM interrupts the cancer treatment course, induces weight loss, and increases the treatment cost (9-12). Thus, the control of OM in cancer treatment is very important.

The risk factors for developing $\mathrm{OM}$ during cancer treatment are not fully understood. Risk factors have been attributed to both the therapy regimen and patient characteristics (13). However, even though diagnosis and treatment may be similar, patients are not at equal risk of mucositis (14). Patient-related risk factors can be complex, including systemic conditions.

Among systemic conditions, renal dysfunction (RD) is one of the basic conditions that should be carefully considered in patients with cancer, and drug dosage adjustments are often necessary in CCRT. Although RD affects the metabolism of anticancer agents (15), the association between RD and OM development during cancer treatment such as CCRT remains unclear. Thus, we hypothesized that RD is a risk factor for 
developing OM in CCRT. The aim of this study was to investigate the association between RD and OM in patients undergoing CCRT for pharyngeal cancer including radiation to the oral cavity. Because the area irradiated in patients with pharyngeal cancer often includes the oral cavity, the inclusion criteria of this study were pharyngeal cancer and treatment with CCRT.

\section{Patients and Methods}

Study design and population. This was a retrospective cohort study. A total of 130 patients were diagnosed as having pharyngeal cancer at the Okayama University Hospital Head and Neck Cancer Center (Okayama, Japan) and received CCRT between April, 2013 and March, 2017. Exclusion criteria were as follows: complete data not acquired (59 patients); irradiated area did not include the oral cavity (25 patients); or edentulous patients (two patients). As a result, data from 44 patients were analyzed (Figure 1).

This study was approved by the Ethics Committee of the Okayama University Graduate School of Medicine, Dentistry and Pharmaceutical Sciences and the Okayama University Hospital (no. 1802-018). Informed consent was obtained from each participant.

General and oral conditions. The data for the general and oral conditions were collected from medical and dental records. These items were age, sex, body weight, smoking habit, drinking habit, medical history, radiation dose, anticancer agent menu, cancer stage (International Classification of Diseases for Oncology ICD-10 version 2015) (16), primary cancer site, center site of the irradiated area, incipient or recurrent cancer, number of teeth present, possible oral factors causing injury to the oral mucosa, nutrition by gastrogavage/nasoenteric, xerostomia, and amount of antiinflammatory gargle agent used. Factors causing injury to the oral mucosa, such as malalignment and remaining tooth roots, were diagnosed by a dentist prior to cancer therapy. Furthermore, serum markers, including white blood cell (WBC) count, serum albumin, serum creatinine, aspartate aminotransferase (AST), alanine aminotransferase (ALT), and C-reactive protein (CRP), were also evaluated. The serum WBC count was determined by the electrical resistance method using an automatic analyzer (BAYER ADVIA2120; Bayer Ltd., Osaka, Japan). The serum Alb level was measured by the modified bromocresol purple method using an automatic analyzer (JEOL BM 8040 and BM 2250; Jeol Ltd., Tokyo, Japan). The serum creatinine level was measured by enzymatic methods using an automatic analyzer (JEOL BM 8040 and JCA-BM 6050; Jeol Ltd.). The serum CRP concentration was measured using the latex agglutination method using an automatic analyzer (JEOL BM 8040 and BM 2250; Jeol Ltd.).

The serum creatinine level ( $\mathrm{SCr}$ ) was converted to creatinine clearance $(\mathrm{Ccr})$ in males by the Cockcroft-Gault equation $(17,18)$, as follows:

$\mathrm{Ccr}(\mathrm{mI} / \mathrm{min})=[140-$ age $($ years $)] \times$ weight $(\mathrm{kg}) \div[72 \times(\mathrm{SCr}+0.2)]$.

For females, Ccr values thus calculated were multiplied by 0.85 . Based on previous studies (19-23), a Ccr cut-off of $60 \mathrm{ml} / \mathrm{min}$ was used. Ccr of $60 \mathrm{mI} / \mathrm{min}$ or less was defined as moderate/severe RD, and $\mathrm{Ccr}$ of $60 \mathrm{mI} / \mathrm{min}$ or more was defined as normal/mild RD.

The scale for OM was according to the Common Terminology Criteria for Adverse Events ver. 3.0 (2006) (24) as follows: 0, None; 1 , erythema of the mucosa; 2 , patchy ulcerations or pseudomembranes;
3, confluent ulcerations or pseudomembranes, bleeding with minor trauma; 4, tissue necrosis, significant spontaneous bleeding, lifethreatening consequences; and 5, death. Treatment plans were determined by standard protocols according to the tumor stage and physical condition of the patient.

Statistical analysis. The patients were divided into two groups according to OM: grade $0-2(\mathrm{~N}=20)$ and grade $3(\mathrm{~N}=24)$; there were no patients with grade 4 or 5 during the study period. The MannWhitney $U$-test and chi-squared test were used to assess significant differences in clinical variables between the two groups. The cumulative incidence of overall OM was estimated using the KaplanMeier method, and differences were tested using the log-rank test. The follow-up period lasted until a CCRT dose of 60 Gy was reached.

Backward stepwise regression procedures for the Cox proportional hazards model were used to determine significant prognostic factors. The variable reduction method (likelihood ratio) was adopted for the Cox proportional hazards model, and the remaining factors were reevaluated using the forced-input method. In the Cox proportional hazards model, the following candidate variables were adjusted for covariates: Smoking habit, drinking habit, incipient cancer, cancer stage, toxicity of anticancer drug agents, number of teeth present, factor causing injury to the oral mucosa, WBC count, serum albumin concentration, center of the irradiated area, and renal dysfunction. Anticancer agents were divided into two categories according to toxicity, either liver or kidney. Values of $p<0.05$ were considered significant. All analyses were performed using SPSS $15.0 \mathrm{~J}$ for Windows (IBM Japan, Tokyo, Japan).

\section{Results}

Table I shows the comparisons of baseline variables and events in CCRT between the two OM groups, grade 0-2 and grade 3 . There were no significant differences in the variables between the two groups, except for $\mathrm{Ccr}$, which was significantly lower in the latter group.

Table II shows the distribution of OM during the CCRT period in the normal/mild RD and the moderate/severe RD groups. There were no significant differences in the distribution of severity between the two groups.

The Cox proportional hazards regression model demonstrated that the nasopharynx/oropharynx as the site of the irradiated area and RD were significantly associated with the incidence of severe OM (grade 3) (Table III). Figure 2 shows the association between RD and the overall incidence of severe OM for non-adjusted and adjusted cases. Figure 3 shows the association between the site of the irradiated area (hypopharynx vs. nasopharynx/oropharynx) and the overall incidence of severe OM for non-adjusted and adjusted cases.

\section{Discussion}

As well as type of CCRT, a variety of factors including age, nutritional status, type of malignancy, pretreatment oral condition, oral care during treatment, and pretreatment neutrophil counts can be associated with the development of 


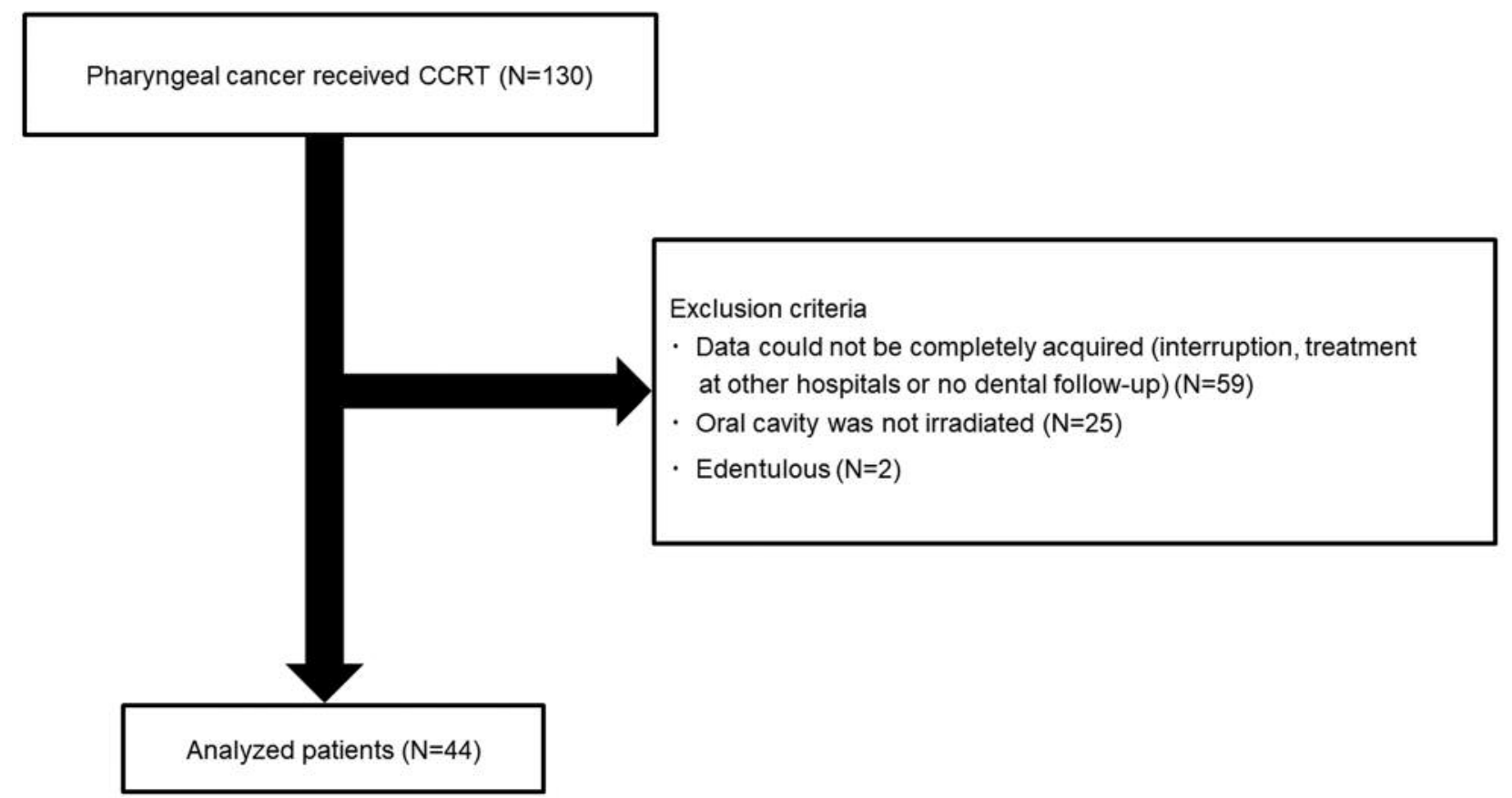

Figure 1. Flowchart of the study. CCRT: Concurrent chemoradiotherapy.

OM in patients with $\operatorname{HNC}(25,26)$. However, the details of the mechanism of $\mathrm{OM}$ development are completely unknown, and its control during CCRT remains challenging. To the best of our knowledge, this is the first longitudinal study to investigate the association between OM and RD during CCRT. The present study showed that the relative high-risk factors for severe OM (grade 3) were the nasopharynx/oropharynx as site of irradiation and RD (Table III). This may provide a new insight into OM and predict developing OM during CCRT by focusing on RD.

It was found that RD was a possible risk factor for severe OM (Table III). Since impaired renal function is associated with decreased renal clearance of drugs, it can lead to high incidences and severities of adverse events in patients taking anticancer agents (22). In CCRT, anticancer agents or molecular target drugs, including cisplatin, carboplatin, methotrexate, tegafur, and cetuximab, are widely used. One of the major side-effects of these anticancer agents is RD (14). Therefore, prescription of anticancer agents should be carefully considered in order to prevent severe $\mathrm{OM}$ in patients with HNC during CCRT in accordance with the estimated Ccr.

When the center of the irradiated area was the nasopharynx/oropharynx, the risk of severe OM was significantly higher than when it was the hypopharynx (Table III, Figure 3). The radiation dose is gradually attenuated from the center of the target lesion to the neighboring area
(27). Since the center of the irradiated area was closer to the oral cavity when the site was the nasopharynx/oropharynx rather than the hypopharynx, it may be reasonable that severe OM developed in cases with the center site being the nasopharynx/oropharynx.

Because of intense pain, patients with grade 3-4 mucositis require feeding tubes, total parenteral nutrition, and opioid analgesics $(12,28)$. Therefore, clinicians should pay attention to nutritional support, oral decontamination, palliation of dry mouth, management of oral bleeding, and therapeutic interventions during the management of OM in patients treated with CCRT (29). In the present study, all patients received continuous oral hygiene care by nurses, dentists, or dental hygienists. When patients have RD and the center site of the irradiated area is the nasopharynx/oropharynx, clinicians should understand the high risk of severe OM before CCRT. Furthermore, more appropriate management of OM is needed in the future.

CCRT is one of the most commonly used cancer treatments, in which severe OM develops at a high rate. CCRT can more easily induce severe OM than radiotherapy alone. Furthermore, the risk of severe OM in radiotherapy without covering the oral cavity, such as intensity-modulated radiation therapy, may be similar to that of chemotherapy alone (27). Since the goal was to investigate more critically the risk of OM in CCRT, CCRT cases in which the irradiated area did not cover the oral cavity were excluded. 
in vivo $33: 183-189(2019)$

Table I. Relationships between grade of oral mucositis and other factors.

Severity of oral mucositis

\begin{tabular}{|c|c|c|c|}
\hline Baseline parameter & Grade $0-2(\mathrm{~N}=20)$ & Grade $3(\mathrm{~N}=24)$ & $p$-Value* \\
\hline \multicolumn{4}{|l|}{ Age (years) } \\
\hline Median (IQR) & $64.0(56.8-68.5)$ & $70.5(62.0-76.0)$ & 0.050 \\
\hline \multicolumn{4}{|l|}{ Gender: n (\%) } \\
\hline Male & $16(80.0)$ & $20(83.3)$ & 0.775 \\
\hline \multicolumn{4}{|l|}{ Body weight $(\mathrm{kg})$} \\
\hline Median (IQR) & $55.3(49.1-60.4)$ & $56.0(49.6-60.7)$ & 0.991 \\
\hline \multicolumn{4}{|l|}{ Habit: n (\%) } \\
\hline Smoking & $16(80.0)$ & $20(83.3)$ & 0.261 \\
\hline Drinking & $15(75.0)$ & $22(91.7)$ & 0.495 \\
\hline \multicolumn{4}{|l|}{ Systemic diseases } \\
\hline No & $2(10.0)$ & $2(8.3)$ & 0.919 \\
\hline Hypertension & $5(25.0)$ & $5(20.8)$ & \\
\hline Diabetes & $1(5.0)$ & $3(12.5)$ & \\
\hline Liver diseases & $3(15.0)$ & $2(8.3)$ & \\
\hline Cancer except for neck cancer & $3(15.0)$ & $3(12.5)$ & \\
\hline Others & $6(30.0)$ & $9(37.5)$ & \\
\hline \multicolumn{4}{|l|}{ Radiation dose (Gy) } \\
\hline Median (IQR) & $60.0(60.0-61.0)$ & $60.0(60.0-60.0)$ & 0.834 \\
\hline \multicolumn{4}{|l|}{ Anticancer agent: $\mathrm{n}(\%)$} \\
\hline Tegafur & $6(30.0)$ & $3(12.5)$ & 0.392 \\
\hline Tegafur + nedaplatin & $3(15.0)$ & $6(25.0)$ & \\
\hline Tegafur + cisplatin & $9(45.0)$ & $10(41.7)$ & \\
\hline Cetuximab & $2(10.0)$ & $5(20.8)$ & \\
\hline \multicolumn{4}{|l|}{ Cancer stage: n (\%) } \\
\hline 0 & $0(0.0)$ & $1(4.2)$ & 0.208 \\
\hline I & $0(0.0)$ & $1(4.2)$ & \\
\hline II & $2(10.0)$ & $0(0.0)$ & \\
\hline III & $7(35.0)$ & $6(25.0)$ & \\
\hline IVA & $10(50.0)$ & $15(62.5)$ & \\
\hline IVB & $0(0.0)$ & $0(0.0)$ & \\
\hline IVC & $1(5.0)$ & $1(4.2)$ & \\
\hline \multicolumn{4}{|l|}{ Primary cancer site: $\mathrm{n}(\%)$} \\
\hline Nasopharynx & $1(5.0)$ & $6(25.0)$ & 0.220 \\
\hline Oropharynx & $6(30.0)$ & $6(25.0)$ & \\
\hline Hypopharynx & $13(65.0)$ & $11(45.8)$ & \\
\hline Multifocal & $0(0.0)$ & $1(4.2)$ & \\
\hline \multicolumn{4}{|l|}{ Center of irradiated area } \\
\hline Nasopharynx or oropharynx & $7(35.0)$ & $13(54.2)$ & 0.204 \\
\hline Hypopharynx & $13(65.0)$ & $11(45.8)$ & \\
\hline \multicolumn{4}{|l|}{ Incipient or recurrent cancer } \\
\hline Incipient & $19(95.0)$ & $24(100.0)$ & 0.268 \\
\hline WBC count $(\mathrm{n} / \mu 1)$ & & & \\
\hline Median (IQR) & $5410.0(4757.5-6467.5)$ & $5345.0(4390.0-6145.0)$ & 0.604 \\
\hline $\mathrm{Alb}(\mathrm{g} / \mathrm{dl})$ & & & \\
\hline Median (IQR) & $4.0(3.8-4.3)$ & $4.0(3.7-4.3)$ & 0.924 \\
\hline $\operatorname{Ccr}(\mathrm{ml} / \mathrm{min})$ & & & \\
\hline Median (IQR) & $62.2(56.1-73.7)$ & $55.2(45.6-61.2)$ & 0.007 \\
\hline $\operatorname{AST}(\mathrm{U} / \mathrm{l})$ & & & \\
\hline Median (IQR) & $20.0(16.8-32.0)$ & $20.0(16.8-25.5)$ & 0.595 \\
\hline $\operatorname{ALT}(\mathrm{U} / \mathrm{l})$ & & & \\
\hline Median (IQR) & $17.5(11.8-24.3)$ & $16.5(13.0-29.0)$ & 0.759 \\
\hline $\mathrm{CRP}(\mathrm{mg} / \mathrm{dl})$ & & & \\
\hline Median (IQR) & $0.2(0.1-0.3)$ & $0.1(0.1-0.3)$ & 0.464 \\
\hline Number of teeth present & & & \\
\hline Median (IQR) & $16.5(10.0-26.0)$ & $21.5(15.5-26.0)$ & 0.345 \\
\hline Factor causing injury to the oral mu & & & \\
\hline $\mathrm{N}(\%)$ & $4(20.0)$ & $4(16.7)$ & 0.775 \\
\hline Event during CCRT: n (\%) & & & \\
\hline Nutrition by gastrogavage & $15(75.0)$ & $21(87.5)$ & 0.284 \\
\hline Nutrition by nasoenteric feeding & $2(10.0)$ & $3(12.5)$ & 0.795 \\
\hline Xerostomia & $14(70.0)$ & $20(83.3)$ & 0.293 \\
\hline Amount of gargle agent (1) & $3.0(2.0-5.8)$ & $3.8(2.6-6.1)$ & 0.635 \\
\hline
\end{tabular}

IQR: Interquartile range; WBC: white blood cell count; Alb: albumin; Ccr: creatinine clearance (converted by Cockcroft-Gault); AST: aspartate aminotransferase; ALT: alanine aminotransferase; CRP: C-reactive protein. CCRT: Concurrent chemoradiotherapy; ${ }^{*}$ Mann-Whitney $U$-test or chisquared test. 
Table II. Relationship between renal dysfunction (RD) and oral mucositis (OM).

\begin{tabular}{lccc}
\hline & & \multicolumn{3}{c}{$\mathrm{RD}, \mathrm{n}(\%)$} \\
\cline { 2 - 4 } OM & Total, $\mathrm{n}(\%)$ & Normal/mild (N=20) & Moderate/severe (N=24) \\
\hline None & $2(4.5)$ & $1(5.0)$ & $1(4.2)$ \\
Grade 1 & $6(13.6)$ & $3(15.0)$ & $3(12.5)$ \\
Grade 2 & $12(27.3)$ & $8(40.0)$ & $4(16.7)$ \\
Grade 3 & $24(54.5)$ & $8(40.0)$ & $16(66.7)$ \\
Grade 4 & $0(0.0)$ & $0(0.0)$ & $0(0.0)$ \\
Grade 5 & $0(0.0)$ & $0(0.0)$ & $0(0.0)$ \\
\hline
\end{tabular}

CCRT: Concurrent chemoradiotherapy; RD: renal dysfunction. patients were divided into those with normal/mild RD (creatinine clearance: Ccr $\geq 60 \mathrm{ml} / \mathrm{min}$ ) and moderate/severe $\mathrm{RD}(\mathrm{Ccr}<60 \mathrm{ml} / \mathrm{min})$ groups. ${ }^{*} \mathrm{Chi}$-squared test.
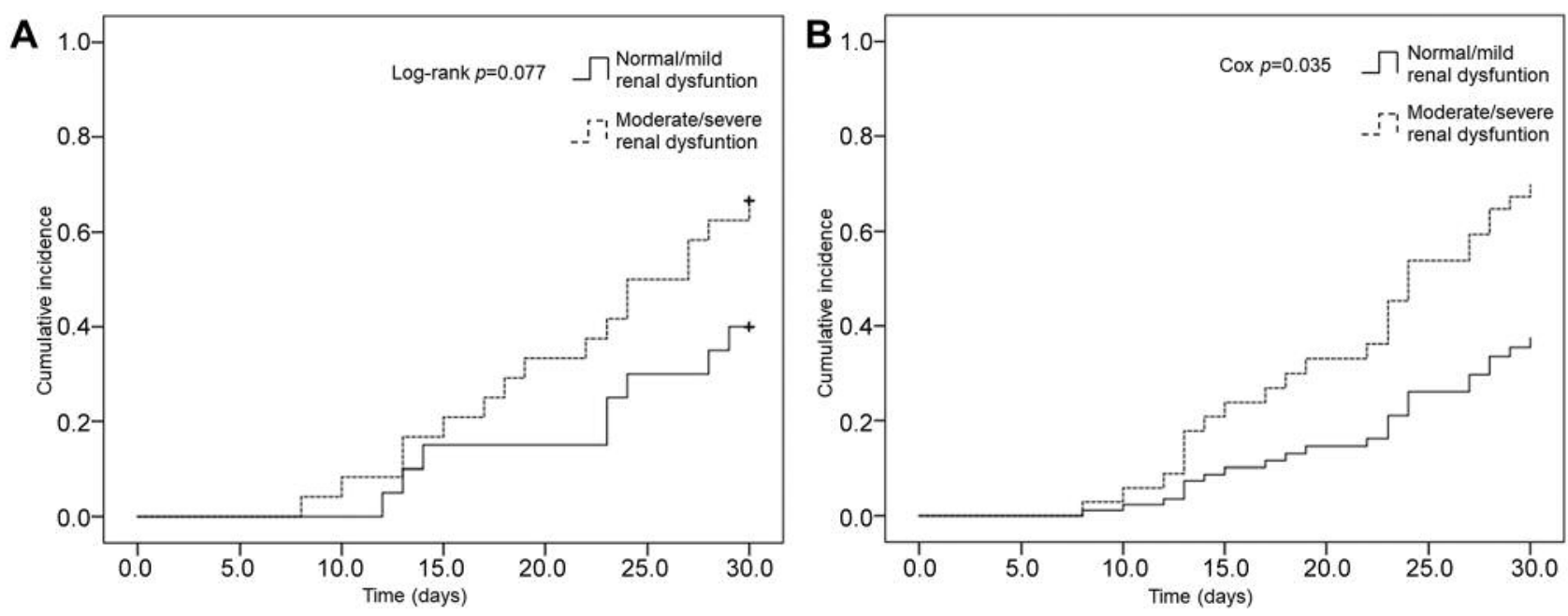

Figure 2. Association between renal dysfunction and overall incidence of oral mucositis (grade 3) for non-adjusted (A) and adjusted (B) cases (adjusted for covariates shown in Table III). Moderate/severe renal function: Creatinine clearance (Ccr) $<60 \mathrm{mI} / \mathrm{min}$; normal/mild renal dysfunction: Ccr $\geq 60 \mathrm{mI} / \mathrm{min}$.
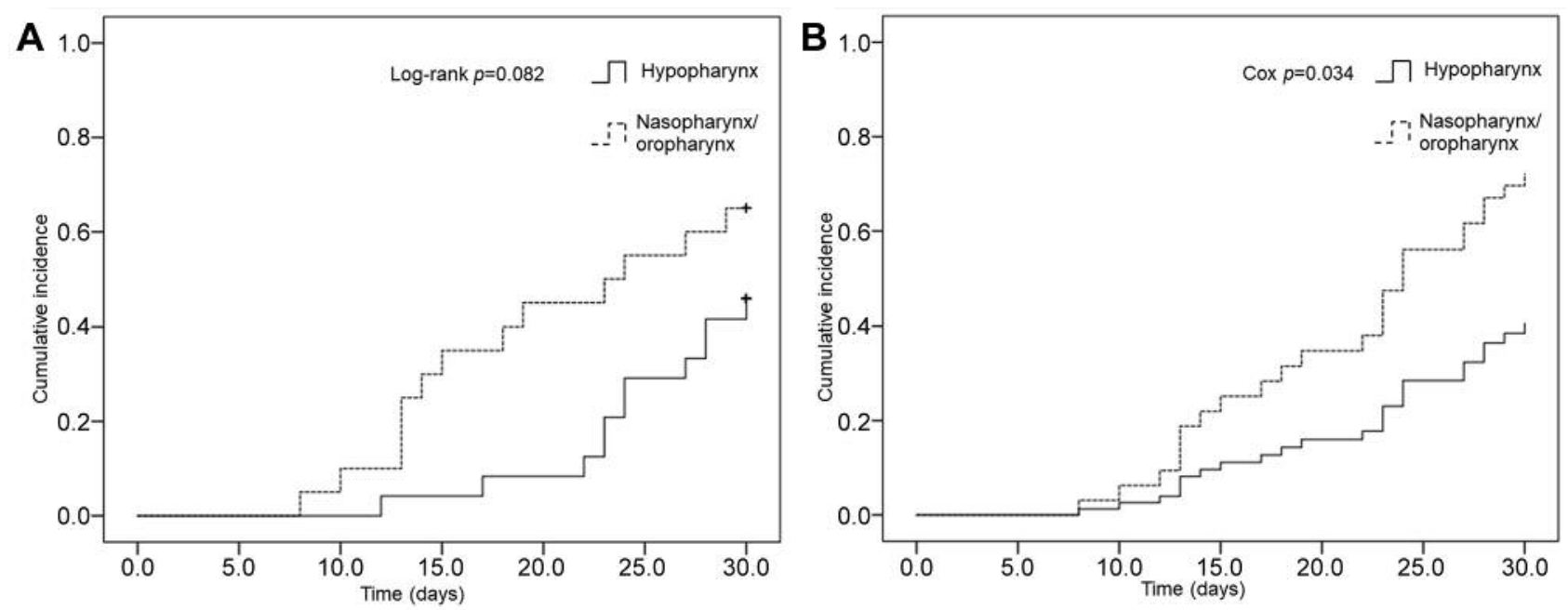

Figure 3. Association between the center site of the irradiated area (hypopharynx vs. nasopharynx/oropharynx) and the overall incidence of oral mucositis (grade 3) for non-adjusted (A) and adjusted (B) cases (adjusted for covariates shown in Table III). 
Table III. Cox proportional hazards model examining prognostic factors.

\begin{tabular}{lccc}
\hline Factor & HR & $95 \%$ CI & $p$-Value* \\
\hline Renal dysfunction & & & \\
$\quad$ Normal/mild & 1.00 & & \\
$\quad$ Moderate/severe & 2.45 & $1.067-6.116$ & 0.035 \\
Center of irradiated area & & & \\
$\quad$ Hypopharynx & 1.00 & & \\
$\quad$ Nasopharynx/oropharynx & 2.56 & $1.072-5.604$ & 0.034 \\
\hline
\end{tabular}

CI: Confidence interval; Ccr: creatinine clearance; HR: hazard ratio; $\mathrm{RD}$ : renal dysfunction; normal/mild RD: Ccr: $\geq 60 \mathrm{ml} / \mathrm{min}$; moderate/severe RD: Ccr $<60 \mathrm{ml} / \mathrm{min}$. *Adjusted for covariates: smoking habit: drinking habit: incipient cancer: cancer stage: toxicity of anticancer drug agents: number of teeth present: factor causing injury to the oral mucosa: white blood cell count: serum albumin concentration: center site of the irradiated area: and renal dysfunction.

A previous study reported that the overall incidence of OM in CCRT was $80 \%$ (30). For severe OM (>grade 2), the incidence was about $45 \%$ in patients receiving CCRT $(10,25,26)$. In the present study, the overall OM incidence was $95.5 \%$, and severe OM was observed in $54.5 \%$ of patients (Table II). On the other hand, in patients receiving a typical course of RT (6-7 weeks), OM appears as erythema of the oral mucosa in the first 2-3 weeks of RT. In the present study, OM appeared 2-3 weeks after the start of CCRT (data not shown). Thus, the prevalence and timing of developing $\mathrm{OM}$ in this study were similar to other studies.

The present study had certain limitations. Firstly, all patients were recruited from the Okayama University Hospital. This may limit the application of our findings to the general population. Secondly, the number of patients was small. Further studies with a larger number of patients are required. Thirdly, this was a retrospective cohort study. Prospective cohort or intervention studies may confirm this relationship. Finally, aIthough there was adjustment for potential confounders, there may be further confounders including oral microflora or genetic factors, and the detailed mechanism relating $\mathrm{RD}$ and $\mathrm{OM}$ remains unknown.

In conclusion, this retrospective study showed that $\mathrm{RD}$ at baseline and nasopharynx/oropharynx as the center of the irradiated area were associated with a high risk of severe OM in patients with pharyngeal cancer those with CCRT including irradiation to the oral cavity.

\section{Conflicts of Interest}

The Authors declare they have no competing interests in regard to this study.

\section{References}

1 Hori M, Matsuda T, Shibata A, Katanoda K, Sobue T and Nishimoto H: Cancer incidence and incidence rates in Japan in 2009: A study of 32 population-based cancer registries for the Monitoring of Cancer Incidence in Japan (MCIJ) project. Jpn J Clin Oncol 45(9): 884-891, 2015.

2 Al-Sarraf M and LeBlanc M, Giri PG, Fu KK, Cooper J, Vuong T, Forastiere AA, Adams G, Sakr WA, Schuller DE and Ensley JF: Chemoradiotherapy versus radiotherapy in patients with advanced nasopharyngeal cancer: phase III randomized Intergroup study 0099. J Clin Oncol 16(4): 1310-1317, 1998.

3 Pignon JP, Bourhis J, Domenge C and Designé L: Chemotherapy added to locoregional treatment for head and neck squamous-cell carcinoma: Three meta-analyses of updated individual data. MACH-NC Collaborative Group. Meta-analysis of chemotherapy on head and neck cancer. Lancet 355(9208): 949-a55, 2000.

4 Monnerat C, Faivre S, Temam S, Bourhis J and Raymond E: End points for new agents in induction chemotherapy for locally advanced head and neck cancers. Ann Oncol 13(7): 995-1006, 2002.

5 Pfister DG, Spencer S, Brizel DM, Burtness B, Busse PM, Caudell JJ, Cmelak AJ, Colevas AD, Dunphy F, Eisele DW, Gilbert J, Gillison ML, Haddad RI, Haughey BH, Hicks WL Jr., Hitchcock YJ, Jimeno A, Kies MS, Lydiatt WM, Maghami E, Martins R, McCaffrey T, Mell LK, Mittal BB, Pinto HA, Ridge JA, Rodriguez CP, Samant S, Schuller DE, Shah JP, Weber RS, Wolf GT, Worden F, Yom SS, McMillian NR, Hughes M; National Comprehensive Cancer Network. Head and neck cancers: Version 2.2014: Clinical practice guidelines in oncology. J Natl Compr Canc Netw 12(10): 1454-1487, 2014.

6 Sroussi HY, Epstein JB, Bensadoun RJ, Saunders DP, Lalla RV, Migliorati CA, Heaivilin $\mathrm{N}$ and Zumsteg ZS: Common oral complications of head and neck cancer radiation therapy: mucositis: infections: saliva change: fibrosis: sensory dysfunctions: dental caries: periodontal disease: and osteoradionecrosis. Cancer Med 6(12): 2918-2931, 2017.

7 Duncan GG, Epstein JB, Tu D, El Sayed S, Bezjak A, Ottaway J and Pater J: Quality of life: mucositis: and xerostomia from radiotherapy for head and neck cancers: a report from the NCIC CTG HN2 randomized trial of an antimicrobial lozenge to prevent mucositis. Head Neck 27(5): 421-428, 2005.

8 Lalla RV, Treister N, Sollecito T, Schmidt B, Patton LL, Mohammadi K, Hodges JS and Brennan MT: Oral complications at 6 months after radiation therapy for head and neck cancer. Oral Dis 23(8): 1134-1143, 2017.

9 Vera-Llonch $\mathrm{M}$ and Oster G, Hagiwara $\mathrm{M}$ and Sonis S: Oral mucositis in patients undergoing radiation treatment for head and neck carcinoma. Cancer 106(2): 329-336, 2006.

10 Trotti A, Bellm LA, Epstein JB, Frame D, Fuchs HJ, Gwede CK, Komaroff E, Nalysnyk L and Zilberberg MD: Mucositis incidence: severity and associated outcomes in patients with head and neck cancer receiving radiotherapy with or without chemotherapy: A systematic literature review. Radiother Oncol 66(3): 253-262, 2003.

11 Wendt TG, Grabenbauer GG, Rödel CM, Thiel HJ, Aydin H, Rohloff R, Wustrow TP, Iro H, Popella C and Schalhorn A: Simultaneous radiochemotherapy versus radiotherapy alone in advanced head and neck cancer: A randomized multicenter study. J Clin Oncol 16(4): 1318-1324, 1998. 
12 Elting LS, Cooksley CD, Chambers MS and Garden AS: Risk: outcomes: and costs of radiation-induced oral mucositis among patients with head-and-neck malignancies. Int J Radiat Oncol Biol Phys 68(4): 1110-1120, 2007.

13 Kashiwazaki H, Matsushita T, Sugita J, Shigematsu A, Kasashi K, Yamazaki Y, Kanehira T, Yamamoto S, Kondo T, Endo T, Tanaka J, Hashino S, Nishio M, Imamura M, Kitagawa $Y$ and Inoue N: Professional oral health care reduces oral mucositis and febrile neutropenia in patients treated with allogeneic bone marrow transplantation. Support Care Cancer 20(2): 367-373, 2012.

14 Shankar A, Roy S, Bhandari M, Rath GK, Biswas AS, Kanodia $\mathrm{R}$, Adhikari N and Sachan R: Current trends in management of oral mucositis in cancer treatment. Asian Pac J Cancer Prev 18(8): 2019-2026, 2017.

15 Fujita K, Masuo Y, Okumura H, Watanabe Y, Suzuki H, Sunakawa Y, Shimada K, Kawara K, Akiyama Y, Kitamura M, Kunishima M, Sasaki Y and Kato Y: Increased plasma concentrations of unbound SN-38: the active metabolite of irinotecan: in cancer patients with severe renal failure. Pharm Res 33(2): 269-282, 2015.

16 World Health Organization (WHO). International Classification of Diseases for Oncology, ICD-10, 10th Revision. Geneva: WHO, 2015

17 Cockcroft DW and Gault MH: Prediction of creatinine clearance from serum creatinine. Nephron 16(1): 31-41, 1976.

18 Ando M, Minami H, Ando Y, Saka H, Sakai S, Yamamoto M, Sasaki Y, Shimokata K and Hasegawa Y: Multi-institutional validation study of carboplatin dosing formula using adjusted serum creatinine level. Clin Cancer Res 6(12): 4733-4738, 2000.

19 Dash A, Galsky MD, Vickers AJ, Serio AM, Koppie TM, Dalbagni $G$ and Bochner BH: Impact of renal impairment on eligibility for adjuvant cisplatin-based chemotherapy in patients with urothelial carcinoma of the bladder. Cancer 107(3): 506513, 2006

20 Maru S, Abe T, Shinohara N, Sazawa A, Maruyama S, Harabayashi T, Suzuki S and Nonomura K: Influence of baseline renal function and dose reduction of nephrotoxic chemotherapeutic agents on the outcome of metastatic urothelial carcinoma: a retrospective study. Int J Urol 19(2): 110-116, 2011.

21 Mitsuzuka K, Yamashita S, Namiki S, Yamada S, Sato K, Saito $\mathrm{H}$, Kaiho $\mathrm{Y}$, Ito A, Nakagawa $\mathrm{H}$ and Arai $\mathrm{Y}$ : Low-dose maintenance gemcitabine-carboplatin chemotherapy could be an alternative to continuous standard chemotherapy for patients with metastatic urothelial carcinoma. Int J Urol 21(11): 11141119, 2014.

22 Yamanaka T, Matsumoto S, Teramukai S, Ishiwata R, Nagai Y and Fukushima M: Analysis of risk factors for severe adverse effects of oral 5-fluorouracil S-1 in patients with advanced gastric cancer. Gastric Cancer 10(2): 129-134, 2007.

23 Shiroyama T, Kijima T, Komuta K Yamamoto S, Minami S, Ogata Y, Okafuji K, Imamura F, Hirashima T, Tachibana I, Kawase I and Kumanogoh A: Phase II tailored S-1 regimen study of first-line chemotherapy in elderly patients with advanced and recurrent non-small cell lung cancer. Cancer Chemother Pharmacol 70(6): 783-789, 2012.
24 National Cancer Institute. Common Terminology Criteria for Adverse Events (CTCAE) ver. 3.0. 2006, available at https://ctep.cancer.gov/protocolDevelopment/electronic_applicati ons/docs/ctcaev3.pdf, last accessed 25/09/2018.

25 Pico JL, Avila-Garavito A and Naccache P, Mucositis: Its occurrence: consequences: and treatment in the oncology setting. Oncologist 3: 446-451, 1998.

26 Borowski B, Benhamou E, Pico JL, Laplanche A, Margainaud JP and Hayat M: Prevention of oral mucositis in patients treated with high-dose chemotherapy and bone marrow transplantation: A randomised controlled trial comparing two protocols of dental care. Eur J Cancer B Oral Oncol 30B(2): 93-97, 1994.

27 Dabaja B, Salehpour MR, Rosen I, Tung S, Morrison WH, Ang KK and Garden AS: Intensity-modulated radiation therapy (IMRT) of cancers of the head and neck: Comparison of splitfield and whole-field techniques. Int J Radiat Oncol Biol Phys 63(4): 1000-1005, 2005.

28 Sonis ST, Elting LS, Keefe D, Peterson DE, Schubert M, HauerJensen M and Bekele BN, Raber-Durlacher J, Donnelly JP and Rubenstein EB: Mucositis Study Section of the Multinational Association for Supportive Care in Cancer; International Society for Oral Oncology. Perspectives on cancer therapy-induced mucosal injury: Pathogenesis: measurement: epidemiology: and consequences for patients. Cancer 100: 1995-2025, 2004.

29 Elting LS, Sonis ST, Epstein JB, Raber-Durlacher JE and Migliorati CA, McGuire DB, Hutchins RD and Peterson DE: Mucositis Study Section of the Multinational Association of Supportive Care in Cancer and the International Society for Oral Oncology. Updated clinical practice guidelines for the prevention and treatment of mucositis. Cancer 109(5): 820-831, 2007.

30 Bourhis J, Sire C, Graff P, Grégoire V, Maingon P, Calais G, Gery B, Martin L, Alfonsi M, Desprez P, Pignon T, Bardet E, Rives M, Geoffrois L, Daly-Schveitzer N and Sen S, Tuchais C, Dupuis O, Guerif S, Lapeyre M, Favrel V, Hamoir M, Lusinchi A, Temam S, Pinna A, Tao YG, Blanchard P, Aupérin A: Concomitant chemoradiotherapy versus acceleration of radiotherapy with or without concomitant chemotherapy in locally advanced head and neck carcinoma (GORTEC 99-02): An open-label phase 3 randomised trial. Lancet Oncol 13(2): $145-153,2012$.
Received August 26, 2018

Revised September 21, 2018

Accepted September 28, 2018 